Research, Society and Development, v. 7, n. 6, p. 01-13, e1476346, 2018

ISSN 2525-3409 (CC BY 4.0)

\title{
A Presença da (In) Segurança Alimentar entre os Beneficiários do Bolsa Família da \\ Região Nordeste do Brasil
}

The Presence of Food (In) Security among the Beneficiaries of the Bolsa Família of the Northeast Region of Brazil

\author{
Ruana Raila de Freitas Araújo \\ Universidade Federal do Rio Grande do Norte, Brasil \\ E-mail: ruanafaalmeida@ hotmail.com \\ José Vilton Costa \\ Universidade Federal do Rio Grande do Norte, Brasil \\ E-mail: josevilton@gmail.com \\ Valdeniz da Silva Cruz Junior \\ Universidade Federal do Rio Grande do Norte, Brasil \\ E-mail: valdeniz.cruz@gmail.com
}

Recebido: 09/04/2018 - Aceito: 26/04/2018

\section{Resumo}

Diversos são os fatores que corroboram para o aumento da desigualdade social no Brasil, dentre eles a pobreza pode ser compreendida como uma situação de falência de capacidades básicas em alcançar certos mínimos aceitáveis. Nesse contexto, necessidades básicas como educação, saúde e acesso a alimentos acabam se tornando privilégio para poucos diante de uma sociedade que apresenta tantas desigualdades. Sendo assim, os Programas de Transferência de Renda Condicionada foram criados visando à quebra desse ciclo Inter geracional de pobreza. Esse estudo tem como objetivo principal analisar a presença da (in) segurança alimentar entre os beneficiários do Programa Bolsa Família da região Nordeste do Brasil. Trata-se de um estudo quantitativo e longitudinal, cujos períodos analisados versam entre 2004, 2009 e 2013. A principal fonte de dados utilizada foi a Pesquisa Nacional por Amostra de Domicílios. O estudo concluiu que houve aumento da percepção de segurança alimentar entre os beneficiários do Bolsa Família na região Nordeste para os períodos supracitados.

Palavras-chave: Desigualdade regional; Pobreza; Políticas públicas. 


\section{Abstract}

Several are the factors that corroborate the increase in social inequality in Brazil, among them poverty can be understood as a situation of failure of basic capacities to achieve certain acceptable minimums. In this context, basic needs such as education, health and access to food end up becoming privileged to a society that presents so many inequalities. Thus, the conditional income transfer programmes were designed to break this intergenerational cycle of poverty. This study aims to analyze the presence of the (in) food safety among the beneficiaries of the Family Scholarship program in the northeastern region of Brazil. It is a quantitative and longitudinal study, whose periods analyzed verse between 2004, 2009 and 2013. The main source of data used was the national survey by sample of households. The study concluded that there was an increase in the perception of food safety among the beneficiaries of the family purse in the northeast region for the aforementioned periods.

Keywords: Regional inequality; Poverty; Public policies.

\section{Introdução}

A pobreza, decorrente das desigualdades sociais, é um óbice diante da busca por igualdade de direitos básicos. É sabido que, constitucionalmente, todos têm direito ao acesso à educação, saúde, moradia e outros aspectos que venham a garantir o bem-estar humano e social. No entanto, cabe ao poder público garantir a sua nação o acesso a tais serviços e dessa forma, reduzir as desigualdades sociais que tanto afetam a realidade das famílias. Nesse sentido, os programas de transferência de renda são alternativas, encontradas pelos governos, para garantir ao seu povo o acesso a serviços básicos.

É no âmbito dessa realidade que em 1996 surgem e se ampliam os Programas de Transferência de Renda Condicionada (PTRC) no Brasil, também denominados de "Rede de Proteção Social". Essa Rede é composta por um conjunto de intervenções compensatórias de natureza focalizada na pobreza e na extrema pobreza cujo objetivo principal é combater a denominada pobreza Inter geracional. Ou seja, os programas são focalizados em famílias que se encontram em situação de pobreza ou extrema pobreza. Essas famílias recebem transferência monetária sob a condição de cumprirem certos requisitos (condicionalidades) para desenvolver certas qualificações e melhorar seu nível educacional, de saúde e nutricional (SILVA, et al: 2015).

O Programa Bolsa Família (PBF), foco do estudo em questão, abordará conceitos e condicionalidades apresentadas pelo programa às famílias beneficiárias, assim como 
resultados observados a partir de bancos de dados cujo objetivo principal é analisar a seguinte questão: "Há presença da (in) segurança alimentar entre as famílias beneficiárias do Programa Bolsa Família na região Nordeste do Brasil?”.

A região Nordeste se apresenta como foco do estudo por apresentar o maior número de beneficiários quando comparado às outras regiões. O presente estudo se justifica por realizar uma análise de uma das condicionalidades do PBF e sua efetividade diante do que foi proposto na elaboração do programa. Nas primeiras seções do estudo será feita uma breve análise sobre os principais programas de renda condicionada existentes no Brasil e o surgimento do PBF. Por conseguinte, serão apresentados os procedimentos metodológicos da pesquisa seguido das análises dos resultados. Por fim, a conclusão acerca do problema da pesquisa cujo foco é a presença da (in) segurança alimentar das famílias beneficiárias do PBF da região Nordeste brasileira.

\section{Uma Breve Descrição dos Programas de Transferência de Renda Condicionada no Brasil e o Programa Bolsa Família}

Diversos são os fatores que corroboram para o aumento da desigualdade social no Brasil, dentre eles a pobreza pode ser compreendida como uma situação de falência de capacidades básicas em alcançar certos mínimos aceitáveis. Nesse contexto, necessidades básicas como educação, saúde e acesso a alimentos acabam se tornando privilégio para poucos diante de uma sociedade que apresenta tantas desigualdades.

Diante da persistência da pobreza absoluta no Brasil, onde há insuficiência de renda para garantir um padrão mínimo de subsistência, os programas de renda, condicionado ou não, tornam-se cruciais para o desenvolvimento de uma sociedade que busca o declínio das desigualdades sociais. Estudos apontam que, em conjunto, as transferências de renda, condicionadas e não, são responsáveis pela redução de $28 \%$ nas desigualdades de rendimentos no país (SOARES, 2006). ${ }^{1}$

À vista disso, criou-se em 1996 o primeiro programa de transferência de renda condicionada federal, o Programa de Erradicação do Trabalho Infantil (PETI). Este tinha como foco crianças de sete a quinze anos que trabalhavam, ou estavam sob o risco de trabalhar, em atividades, insalubres ou degradantes - como carvoarias ou canaviais. $\mathrm{O}$ valor pago às famílias rurais era de $\mathrm{R} \$ 25,00$. Posteriormente foi expandido para as áreas urbanas e

\footnotetext{
${ }^{1}$ Como o estudo trata-se apenas do Programa Bolsa Família, buscou-se não abordar assuntos referentes aos programas de transferência de renda não condicionadas.
} 
o valor corrigido para $\mathrm{R} \$ 40,00$ por criança. Suas condicionalidades seriam que crianças menores de 16 anos não trabalhassem e tivessem frequência escolar mínima de $75 \%$ no ano. O Órgão responsável pelo PETI era a Secretaria de Estado e Assistência Social (SEAS). Em 2005 ocorreu a integração do PETI ao Programa Bolsa Família (BRASIL, 2015).

Após o PETI, o segundo programa de transferência de renda condicionada federal no Brasil foi o Programa Bolsa Escola Federal, que teve sua criação em 2001 cuja responsabilidade era do Ministério da Educação. A contrapartida consistia na frequência mínima de $85 \%$ à escola, no ano, para crianças de seis a quinze anos. $\mathrm{O}$ valor do benefício era de $\mathrm{R} \$ 15,00$ por criança, com um teto de $\mathrm{R} \$ 45,00$ por família. Concedido a famílias cuja renda per capita se situava abaixo de $\mathrm{R} \$ 90,00$ (BRASIL, 2015).

Ainda em 2001, houve a criação do Bolsa Alimentação cujas contrapartidas eram: aleitamento materno, exames pré-natais para gestantes e vacinação das crianças. O valor da Bolsa era de $\mathrm{R} \$ 15,00$ por criança com idades entre zero e seis anos com teto de $\mathrm{R} \$ 45,00$ por família. A responsabilidade do Bolsa Alimentação ficava a cargo do Ministério da Saúde. Posteriormente, em 2003, foi criado um quarto programa, o Cartão Alimentação. Tratava-se de um benefício com valor de $\mathrm{R} \$ 50,00$ por família cuja renda per capita não alcançasse meio salário mínimo. Como condicionalidade, os recursos deveriam ser usados na compra de alimentos (BRASIL, 2015).

Um estudo realizado pelo Instituto de Pesquisa Econômica Aplicada (IPEA) divulgado em 2009 sobre o Programa Bolsa Família trouxe uma discussão sobre o início do Programa. Segundo Soares (2009), Cada um desses programas sociais citados anteriormente tinha sua própria agência executora e a coordenação entre elas era mínima. Em suma, havia uma separação dos sistemas de informação desses programas e eles não se comunicavam, de modo que uma família poderia receber benefício de todos os quatro programas, enquanto outra, em condições iguais, poderia não receber transferência nenhuma.

Ainda segundo Soares (2009), isso tornava a coordenação entre os programas federais muito difícil. Pois nenhum dos programas cobria todo o território nacional, e ainda havia a existência dos programas estaduais e municipais. Com essa falta de coordenação, a garantia de proteção social era praticamente inexistente. Porém, todos os programas de todas as esferas reconheciam ser a pobreza um risco social e tinham como público alvo indivíduos de domicílios pobres, de todas as linhas de pobreza. Faltava então, uma reforma gerencial.

Foi então que em outubro de 2003 o Governo Federal criou o Programa Bolsa Família, também citado pela sigla PBF, através da medida provisória $\mathrm{n}^{\circ} 132$, transformado na Lei $\mathrm{n}^{\circ}$ 10.836, de 09 de janeiro de 2004, e regulamentado pelo Decreto $\mathrm{n}^{\circ} 5.209$, de 17 de setembro 
de 2004, sendo considerado como principal programa de transferência de renda condicionada do governo brasileiro cujo objetivo principal era unificar os quatro programas anteriores. Além disso, procurou unificar as ações dos governos federal, estadual e municipal em um único programa de transferência direta de renda por meio de convênios. Além da transferência de valores, o Programa garante as famílias beneficiárias o acesso a serviços básicos, como educação e saúde (BRASIL, 2004).

O Órgão responsável pelo Programa é a Secretaria Nacional de Renda de Cidadania (SENARC), do Ministério do Desenvolvimento Social e Combate à Fome (MDS). É a SENARC que estabelece as normas para a execução, define os valores do benefício, estabelece o diálogo com os municípios, define e acompanha as contrapartidas, estabelece as metas e propõem o orçamento anual do PBF, acompanha o andamento do programa em geral e faz avaliações regulares do PBF. Cabe à SENARC também estabelecer os critérios de quem recebe e quanto recebe, além do critério para suspensão e corte do benefício (SOARES, 2009).

Já a Caixa Econômica Federal é o órgão operador e pagador. É ela quem recebe as informações que compõem o Cadastro Único, levantadas pelos municípios, processa essas informações, calcula a renda familiar per capita de acordo com os critérios estabelecidos pela SENARC, calcula quanto deve receber cada família, emite os cartões magnéticos para pagamento e, por fim, realiza o pagamento dos benefícios mensalmente (BRASIL, 2016).

O Cadastro Único serve como base de informações para o PBF, porém o Cadastro único vai além do PBF e serve como fonte de informação para diversos outros programas. Cabe ao município cadastrar as famílias pobres, usando o questionário padrão definido pela SENARC, e fazer relatórios de acompanhamentos das condicionalidades

\subsection{Principais condicionalidades do programa Bolsa Família}

O PBF é direcionado às famílias em estado de extrema pobreza que possuem renda per capita menor que R \$ 85,00, ou aquelas famílias em estado de pobreza, que possuem renda per capita de $\mathrm{R} \$ 85,01$ a $\mathrm{R}$ \$ 170,00. Além disso, famílias que possuem em sua composição crianças/adolescentes com idade limite de até 17 anos que frequentem a escola regularmente e/ou gestantes também tem direito ao benefício (BRASIL, 2004).

O PBF apresenta como uma de suas dimensões para o enfrentamento da fome e da pobreza o reforço ao exercício de direitos sociais básicos nas áreas de saúde e educação, através do acompanhamento das condicionalidades cujo objetivo principal é: "Elevar o grau 
de efetivação de direitos sociais por meio do acesso aos serviços sociais básicos de saúde, educação e assistência social" (SENARC, 00-10, p.04). Contribuindo assim, para a redução da pobreza entre as gerações (BRASIL, 2004).

Nesse sentido, as condicionalidades do PBF se apresentam dividas nas áreas de saúde, educação e assistência social. Onde, na área da saúde são acompanhadas crianças de até 7 anos cujo acompanhamento é direcionado ao seu crescimento e desenvolvimento, além do acompanhamento das gestantes e nutrizes, através do acompanhamento do pré-natal quando gestantes e, nutrizes. Na área da educação o público alvo são crianças e adolescentes entre 6 e 15 anos onde, é exigida uma frequência mínima de $85 \%$ mensal e, para os jovens de 16 e 17 anos, a frequência mensal exigida é de $75 \%$. Na área de assistência social o público alvo são crianças até 15 anos cujo acompanhamento é voltado aos serviços socioeducativos e de convivência (BRASIL, 2004).

De acordo com uma pesquisa nacional, realizada pelo IBASE, em 2008, referente às repercussões do PBF na segurança alimentar e nutricional das famílias beneficiárias, o dinheiro do PBF é gasto principalmente com alimentação (87\%), seguido de material escolar (37\%) e vestuário (22\%). Além disso, a pesquisa também evidenciou que as famílias beneficiadas com o PBF gastam, em média, R $\$ 200,00$ mensais com alimentação, ou seja, $56 \%$ da renda familiar total (BRASIL, 2008).

\subsection{Segurança alimentar e nutricional e o programa Bolsa Família}

Em 1994 realizou-se a I Conferência Nacional de Segurança Alimentar no Brasil, que reuniu mais de dois mil delegados de todo o país, com forte presença da sociedade civil. Nesta Conferência, a Segurança Alimentar e Nutricional (SAN) foi definida como um componente estratégico de governo que abrangia um conjunto de princípios, além de políticas e estratégias que assegurassem o acesso de todos os cidadãos brasileiros aos alimentos, a preços adequados, em quantidade e qualidade necessárias para atender a exigência nutricional para uma vida saudável e digna (MACHADO, et al: 2011). Nesse sentido, a alimentação e a nutrição constituem requisitos fundamentais para a promoção e proteção à saúde sendo, o direito à alimentação, inserido no contexto de direito à vida, dignidade, autodeterminação e da satisfação das necessidades básicas.

As questões que envolvem a SAN, por definição, comportam dimensões sociais, econômicas, políticas, culturais e de saúde. No Brasil, tradicionalmente, as diferenças sociais vêm sendo monitoradas mediante variáveis sociais e econômicas, como renda, escolaridade e 
esperança de vida ao nascer. A Escala Brasileira de Insegurança Alimentar (EBIA) mede a experiência e a percepção de insegurança alimentar e fome no nível familiar. Sendo assim, a SAN é medida de acordo com os resultados da aplicação da EBIA (BRASIL, 2014).

Pesquisas como a Pesquisa Nacional de Demografia e Saúde da Criança e da Mulher (PNDS, 2006) e a Pesquisa Nacional por Amostra de Domicílios (PNAD, 2009), realizaram levantamentos da situação da SAN nos domicílios brasileiros utilizando a EBIA. Cujos resultados mostraram que, para a PNDS (2006), 37,5\% dos domicílios pesquisados estavam em situação de Insegurança Alimentar (IA), variando de 25\% nos domicílios da região Sul, e 55\% para a região Nordeste. Já a PNAD (2009) constatou que, entre 2004 e 2009, houve redução da proporção de domicílios com moradores em situação de IA tanto na zona urbana (de 33,3\% para 29,4\%), quanto na rural (de 43,6\% para 35,1\%) (BRASIL, 2010).

Ademais, a PNAD (2009) confirmou que quanto menor a classe de rendimento mensal domiciliar per capita, maior a proporção de domicílios em situação de IA moderada ou grave. Para os domicílios nessas condições, 55\% estavam na classe de rendimento mensal per capita de até meio salário mínimo, e 1,9\% estavam na classe de mais de 2 salários mínimos (MACHADO, et al: 2011).

Destarte, ao aumentar o poder aquisitivo das famílias, o PBF contribui para o acesso ao alimento, tanto em termos quantitativos, quanto qualitativos. Porém, mesmo o PBF sendo o maior programa de transferência condicionada de renda do mundo, os estudos científicos na população brasileira são escassos e controversos, o que gera dúvidas sobre o quanto o programa pode influenciar na saúde de seus beneficiários de maneira efetiva, incluindo as dimensões relacionadas a San das famílias (MACHADO, 2011; VETTORE \& LAMARCA, 2011).

\section{Metodologia}

Trata-se de uma abordagem predominantemente quantitativa cuja classificação é descritiva. Considerado um estudo longitudinal, pois aborda os períodos entre 2004, 2009 e 2013. O principal banco de dados utilizado para colher informações sobre os usuários do PBF no período supracitado foi a Pesquisa por Amostra de Domicílios (PNAD), sendo o Ministério do Desenvolvimento Social (MDS) e o Instituto Brasileiro de Análises Sociais e Econômicas (IBASE) fontes de dados secundárias. O universo da pesquisa foram todos os usuários beneficiários do PBF da região Nordeste do Brasil entrevistados pela PNAD. 
A PNAD, ao tratar dos assuntos relacionados à segurança alimentar, baseia-se na escala da EBIA cujo objetivo é mensurar a percepção das famílias em relação ao acesso aos alimentos. Inicialmente, esse método foi implantado nos Estados Unidos na década de 90 pelo Departamento de Agricultura dos EUA (USDA). Posteriormente, em 2003, adaptado e validado pela Unicamp e utilizado em diversas pesquisas, além da PNAD $(2004,2009)$ e PNDS (2006) já citadas, têm os Censos das Comunidades Quilombolas Tituladas com foco em Segurança Alimentar e Nutricional (MDS, 2012), o estado de segurança alimentar e nutricional no Brasil: um retrato multidimensional (FAO, 2014), entre outros inúmeros estudos acadêmicos.

O questionário da EBIA é composto de 14 perguntas e versam sobre a situação alimentar vivenciada no domicílio dos últimos 90 dias em que antecederam a entrevista. São atribuídos pontos às respostas de "Sim" e "Não", sendo a pontuação maior quando o domicílio tem pelo menos um morador menor de 18 anos de idade como exemplificado na Tabela 1 (BRASIL, 2013).

Tabela 1 - Escala de Pontuação da EBIA a partir das respostas dos entrevistados

\begin{tabular}{|c|c|c|}
\hline Classificação & $\begin{array}{c}\text { Pontos de corte para } \\
\text { domicílios com pelo menos } \\
\text { um morador com menos de } \\
18 \text { anos de idade }\end{array}$ & $\begin{array}{c}\text { Pontos de corte para } \\
\text { domicílios sem moradores } \\
\text { com menos de } 18 \text { anos de } \\
\text { idade }\end{array}$ \\
\hline Segurança alimentar & 0 & 0 \\
\hline $\begin{array}{l}\text { Insegurança alimentar leve } \\
\text { Insegurança alimentar }\end{array}$ & 1 a 5 & 1 a 3 \\
\hline moderada & 6 a 9 & 4 a 5 \\
\hline Insegurança alimentar grave & 10 a 14 & 6 a 8 \\
\hline
\end{tabular}

Fonte: IBGE, PNAD, 2013.

Onde, a Segurança Alimentar é medida através do acesso regular e permanente a alimentos de qualidade e em quantidade suficiente, e sequer se sentiam na iminência de sofrer restrição no futuro próximo. Já a Insegurança Alimentar Leve (IA leve) é a preocupação ou a incerteza quanto à disponibilidade de alimentos no futuro em quantidade e qualidade adequadas. Na Insegurança Alimentar Moderada (IA moderada) ocorre na redução quantitativa de alimentos e/ou a ruptura nos padrões de alimentação resultante da falta de alimentos entre os adultos. E a Insegurança Alimentar Grave (IA grave) expressa a redução quantitativa de alimentos e/ou a ruptura nos padrões de alimentação resultante da falta de alimentos entre adultos e/ou crianças; e privação de alimentos; fome (BRASIL, 2013). 
Sendo assim, a partir da classificação da EBIA e dos resultados apresentados na PNAD para os anos de 2004, 2009 e 2013, pôde-se analisar a presença ou não da insegurança alimentar entre os beneficiários do PBF.

\section{Análise e Discussão dos Resultados}

O presente estudo avaliou, inicialmente, o percentual de cobertura do PBF nas famílias totalmente acompanhadas na região Nordeste desde a segunda vigência do ano de 2005 até a segunda vigência do ano de 2016. Os resultados estão expostos no Gráfico 1.

Gráfico 1 - Cobertura do Programa Bolsa Família por regiões e Brasil para os anos de 2005 a 2016

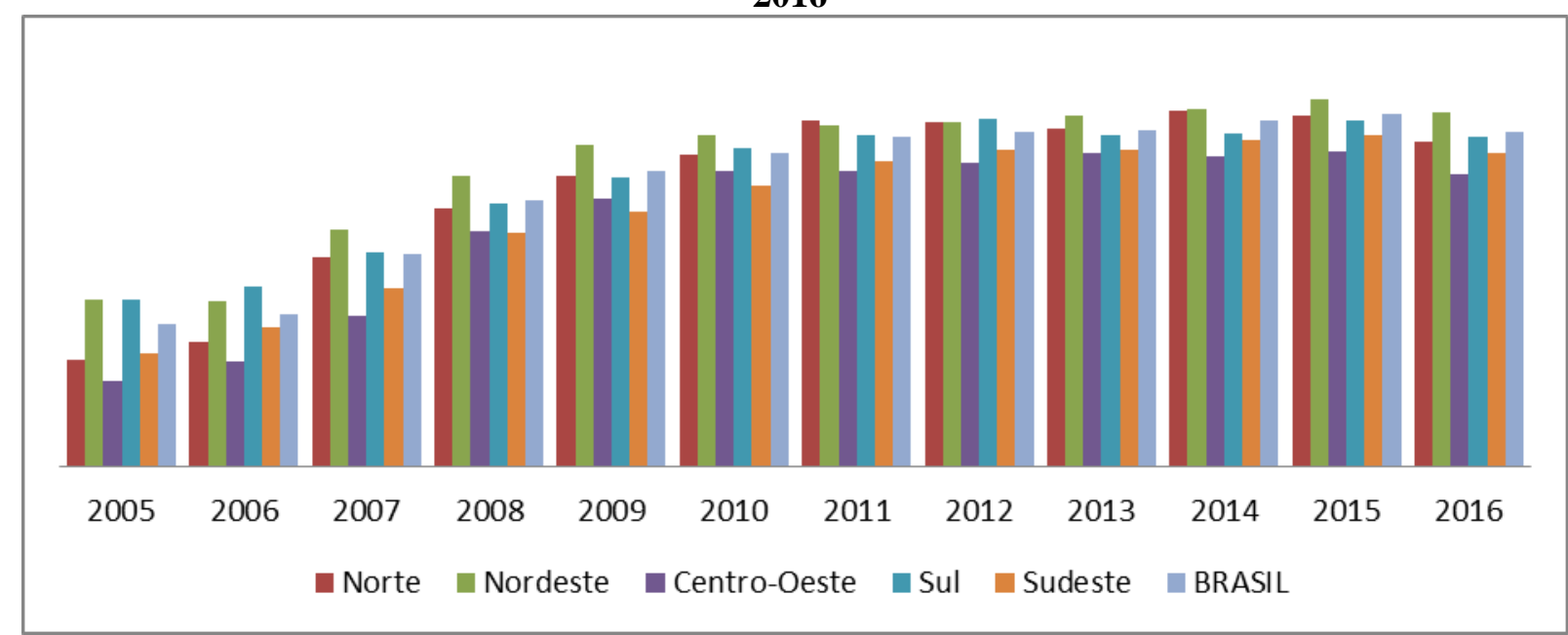

Fonte: MDS, 2016.

Como resultado, notou-se um aumento no percentual de cobertura do PBF em famílias totalmente acompanhadas ao longo dos anos, apresentando seu maior resultado na segunda vigência do ano de 2015, com 80,07\% do total de famílias para acompanhamento. Em 2005, cerca de um ano após a regulamentação do programa, o percentual de cobertura era de $36,39 \%$ na região Nordeste chegando a 77,09\% na segunda vigência de 2016. Quase 11 anos depois de sua implantação, o PBF aumentou seu grau de cobertura em 40,7\%.

Nesse sentido, quando se avalia o percentual de San entre os beneficiários do Bolsa Família para os anos de 2004, 2009 e 2013 na região Nordeste, os resultados na Tabela 2 mostram que houve um aumento no percentual de domicílios com segurança alimentar e uma diminuição de domicílios com insegurança alimentar. 
Research, Society and Development, v. 7, n. 6, p. 01-13, e1476346, 2018

ISSN 2525-3409 (CC BY 4.0)

Tabela 2 - Situação de segurança alimentar existente no domicílio das famílias beneficiárias do Bolsa Família da região Nordeste para os anos de 2004, 2009 e 2013

Nordeste

Situação de segurança alimentar existente no domicílio

\begin{tabular}{ccccc}
\hline \multicolumn{5}{c}{ Com } \\
$\begin{array}{c}\text { segurança } \\
\text { alimentar (\%) }\end{array}$ & Total & Leve & Moderada & Grave \\
\cline { 2 - 5 } & 52,68 & 22,57 & 17,33 & 12,78 \\
47,31 & 46,63 & 25,37 & 11,92 & 9,34 \\
53,37 & 39,12 & 24,46 & 9,29 & 5,37 \\
60,88 & \multicolumn{4}{l}{} \\
\hline
\end{tabular}

Fonte: PNAD, 2004, 2009 e 2013.

Observa-se uma redução importante nos domicílios que apresentavam insegurança alimentar grave, reduzindo de $12,78 \%$ em 2004, para 5,37\% em 2013. Contudo, os percentuais encontrados nos domicílios com insegurança alimentar leve apresentaram aumento de $1,89 \%$ entre os anos de 2004 e 2013. Para insegurança alimentar moderada e grave, os índices diminuíram com uma variação de 8,04\% na IA moderada e, 7,41\% na IA grave. Já os domicílios que apresentaram índices de segurança alimentar na região Nordeste de $47,31 \%$ em 2004, obtiveram um aumento $13,57 \%$ em 2013 , resultando em $60,88 \%$ dos domicílios em segurança alimentar.

Segundos dados da PNAD (2009), no ano de 2008, as famílias beneficiárias do PBF da região Nordeste gastavam cerca de $77,81 \%$ da sua renda mensal com alimentação no domicílio em relação à despesa com alimentação total. Resultado que vai ao encontro da pesquisa realizada pelo Instituto Brasileiro de Análises Sociais e Econômicas (IBASE, 2008), que entrevistou 5 mil titulares do PBF e revelou que 87\% das famílias no Brasil, utilizam os recursos do PBF, principalmente, em gastos com alimentação, como expresso no Gráfico 2. 
Research, Society and Development, v. 7, n. 6, p. 01-13, e1476346, 2018

ISSN 2525-3409 (CC BY 4.0)

Gráfico 2 - Principais uso dos recursos dos beneficiários do PBF em 2008

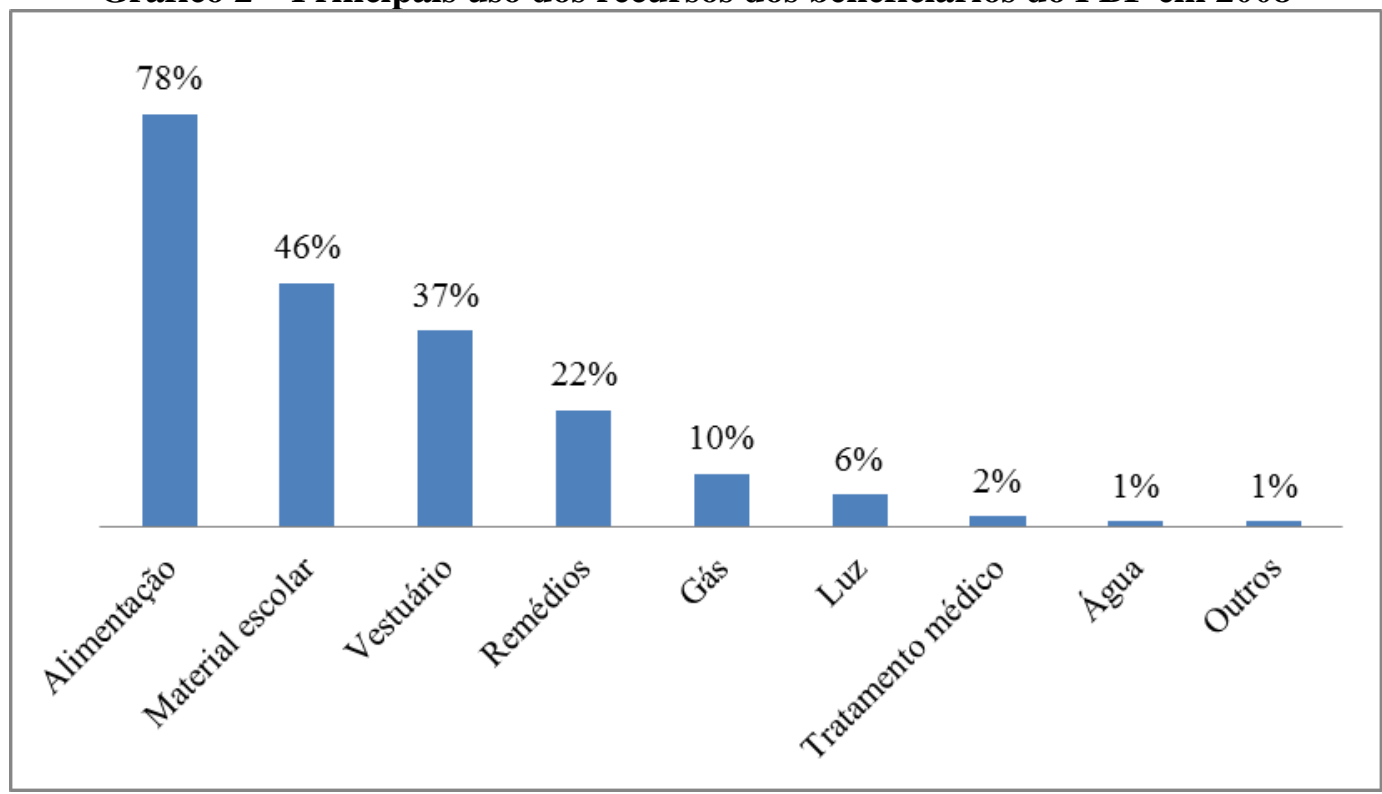

Fonte: IBASE, 2008.

Nesse sentido, entende-se que quanto mais pobre a família maior a proporção de renda gasta com alimentação. Na região Nordeste, em 2004, 44,45\% dos beneficiários do PBF se encontravam em extrema pobreza, ou seja, famílias que vivem com renda menor que $\mathrm{R} \$$ 85,00 per capita. Em 2009, esse percentual era de $27 \%$ e em 2010, reduziu para $18,02 \%$ de famílias beneficiárias que vivem em situação de extrema pobreza na região Nordeste (BRASIL, 2013; 2009). No Gráfico 3 estão expressos o padrão de consumo dos beneficiários do PBF da região Nordeste para o ano de 2010.

Gráfico 3 - Padrão de consumo dos beneficiários do PBF do Nordeste brasileiro em 2010

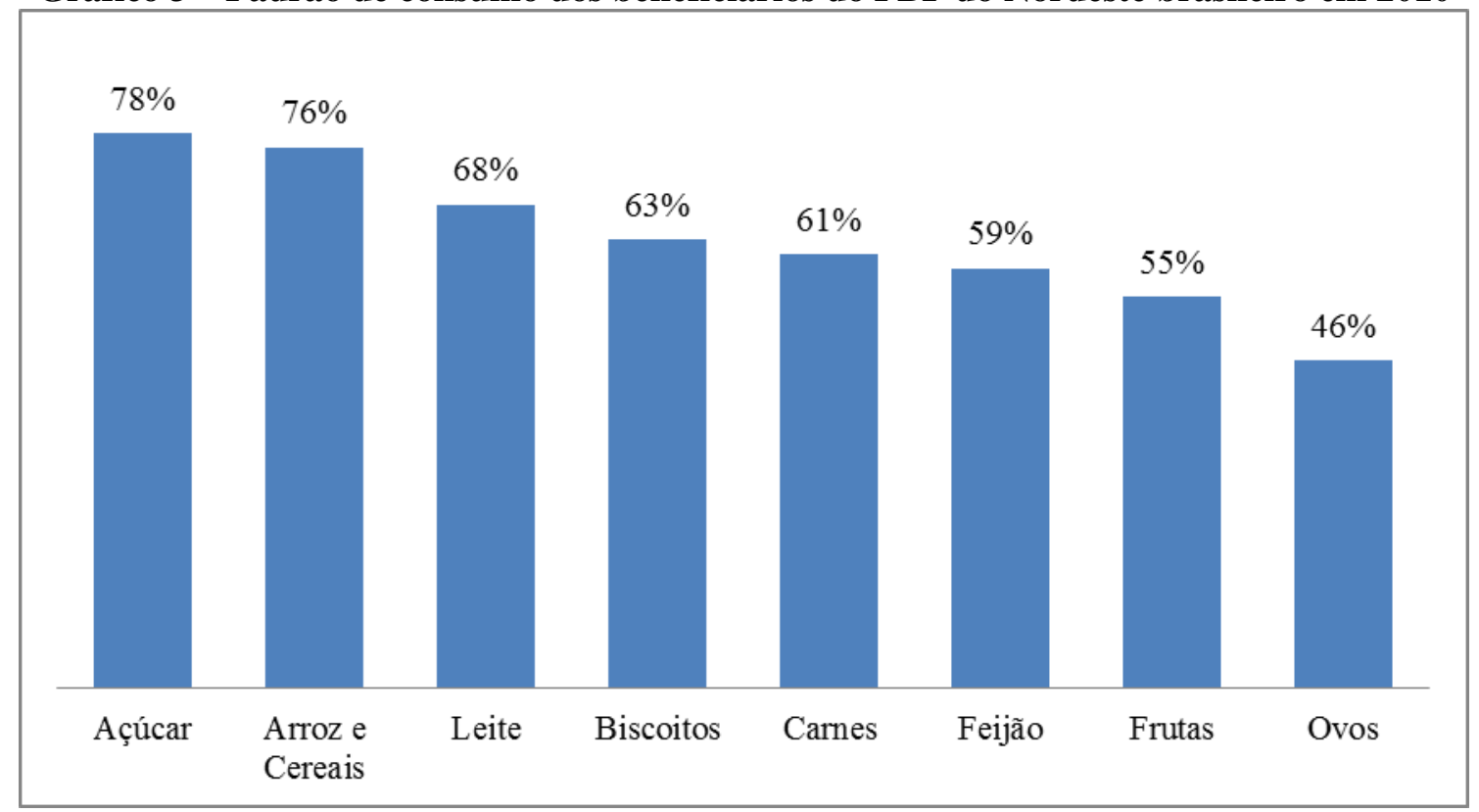

Fonte: IBASE, 2010. 
Esse incremento na renda das famílias beneficiárias corroborou para o aumento no consumo de todos os grupos de alimentos, com menor proporção de leite e seus derivados. Aumentando assim, o consumo de açúcares (78\%), arroz e cereais (76\%), leite (68\%), biscoitos (63\%), carnes (61\%), feijão (59\%), frutas (55\%), ovos (46\%) entre outros. Sendo assim, a regularidade no aporte de recursos propiciada pelo programa possibilita planejar gastos e, consequentemente, modificar o padrão de consumo (BRASIL, 2008).

\section{Conclusão}

Infere-se, a partir dos resultados supracitados, que houve redução da insegurança alimentar entre as famílias beneficiárias do PBF na região Nordeste como um todo, no período analisado. Em contrapartida, a percepção de segurança alimentar, que no ano da implantação do programa, em 2004, era de 47,31\%, passa a ser, em 2013, de 60,88\%. Nesse sentido, a percepção de insegurança alimentar apresentou uma redução de 13,7\% entre as famílias beneficiárias do PBF do Nordeste brasileiro. Tendo, a percepção de insegurança alimentar grave, apresentado uma redução de 7,4\%. Ou seja, não houve apenas o aumento da percepção de segurança alimentar entre as famílias, mas houve uma redução percentual considerável de famílias beneficiárias que, em 2004, encontrava-se em situação de insegurança alimentar grave.

Atrelado a isso, observou-se que o uso dos recursos recebidos por essas famílias corroborou para o alcance desse resultado. Assim como as mudanças apresentadas no padrão de consumo, onde se observou um aumento no consumo de alimentos que trazem segurança alimentar para as famílias, tais quais ovos, leites, carnes entre outros.

Destarte, pode-se inferir que houve redução da percepção de insegurança alimentar entre as famílias beneficiárias do PBF da região Nordeste nos períodos analisados, assim como o aumento da percepção de segurança alimentar entre essas famílias. Em consonância, a diminuição das famílias em situação de extrema pobreza. Porém, faz-se necessária a realização de novos estudos cujo foco seja fatores relacionados à melhoria da qualidade de vida dos beneficiários do PBF, tais como o avanço do desempenho escolar por parte dos dependentes e sua relação com a redução do trabalho infantil, por exemplo. Para que, dessa forma, possa-se avaliar se está havendo efetividade no cumprimento das outras condicionalidades do Programa. 


\section{Referências}

Instituto Brasileiro de Análises Sociais e Econômicas, IBASE. Diálogos sobre o direito humano à alimentação no Brasil. II Etapa da Pesquisa Repercussões do Programa Bolsa Família na Segurança Alimentar e Nutricional. Relatório Final. Rio de Janeiro, 2008. Disponível em: <http://www.ibase.br/userimages/Relatorio_2.pdf>. Acesso em: 20 de novembro de 2017.

MINISTÉRIO DO DESENVOLVIMENTO SOCIAL, MDS. Ação Estratégica do Programa de Erradicação Infantil. Disponível em: < http://mds.gov.br/assuntos/assistenciasocial/servicos-e-programas/peti>. Acesso em: 11 de novembro de 2017.

. Bolsa Família: Matriz de Informações Sociais. 2010-2013. Disponível em: < http://mds.gov.br/assuntos/bolsa-familia/dados>. Acesso em: 17 de novembro de 2017.

PESQUISA NACIONAL POR AMOSTRA DE DOMICÍlIOS, PNAD. Segurança Alimentar. 2004. Disponível em:

<https://ww2.ibge.gov.br/home/estatistica/pesquisas/pesquisa_resultados.php?id_pesquisa=40 $>$ Acesso em: 20 de novembro de 2017.

Segurança Alimentar. 2009. Disponível em:

<https://ww2.ibge.gov.br/home/estatistica/pesquisas/pesquisa_resultados.php?id_pesquisa=40 >. Acesso: em 20 de novembro de 2017.

SILVA, M. O. S. et al. Programas de Transferência de Renda na América Latina: contextualização, a pobreza em foco e os significados e controvérsias do potencial das condicionalidades para formação do capital humano e social. VII Jornada Internacional de Políticas Públicas. 2015. Disponível em: $<$ http://www.joinpp.ufma.br/jornadas/joinpp2015/pdfs/mesas/programas-de-transferencia-derenda-na-america-latina_contextualizacao.pdf >. Acesso em: 11 de dezembro de 2017.

SOARES, F.V., SOARES S, Medeiros M, OSÓRIO RG. Cash Transfer Programs in Brazil. Impacts on inequality and poverty . Working Paper 21. Brasília: UNDP/IPEA; 2006

SOARES, Sergei; SÁTYRO, Natália. O Programa Bolsa Família: Desenho Institucional, impactos e possibilidades futuras, Texto para discussão, Instituto de Pesquisa Econômica Aplicada (IPEA), No. 1424, 2009. 